\title{
Validation Study of Rajasekaran's Kyphosis Classification System: Do We Clearly Understand Single- and Two-Column Deficiencies?
}

\author{
Ajoy Prasad Shetty ${ }^{1}$, Rajesh Rajavelu ${ }^{1}$, Vibhu Krishnan Viswanathan ${ }^{1}$, Kota Watanabe ${ }^{2}$, \\ Harvinder Singh Chhabra ${ }^{3}$, Rishi Mukesh Kanna ${ }^{1}$, Jason Pui Yin Cheung ${ }^{4}$, Yong Hai ${ }^{5}$, Mun Keong Kwan ${ }^{6}$, \\ Chung Chek Wong ${ }^{7}$, Gabriel Liu ${ }^{8}$, Saumajit Basu ${ }^{9,10}$, Abhay Nene ${ }^{11,12,13,14,15}$, J. Naresh-Babu ${ }^{16}$, Bhavuk Garg ${ }^{17}$

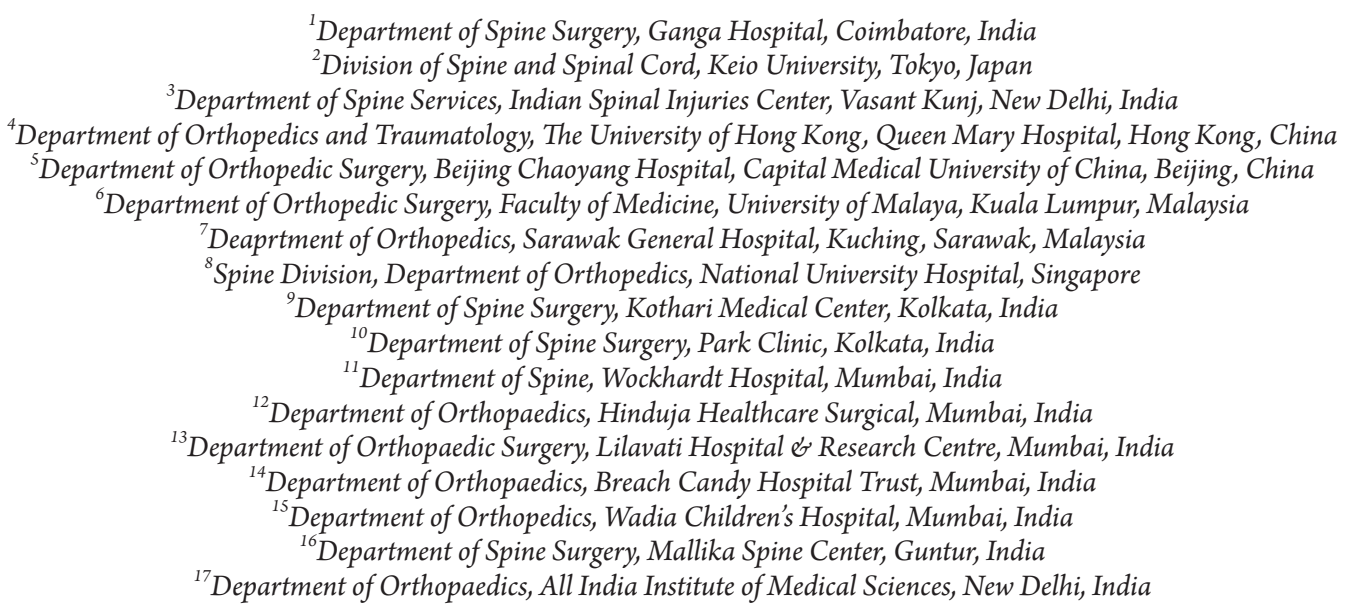

Study Design: Multicenter validation study.

Purpose: To evaluate the inter-rater reliability of Rajasekaran's kyphosis classification through a multicenter validation study. Overview of Literature: The classification of kyphosis, developed by Rajasekaran, incorporates factors related to curve characteristics, including column deficiency, disc mobility, curve magnitude, and osteotomy requirements. Although the classification offers significant benefits in determining prognosis and management decisions, it has not been subjected to multicenter validation. Methods: A total of 30 sets of images, including plain radiographs, computed tomography scans, and magnetic resonance imaging scans, were randomly selected from our hospital patient database. All patients had undergone deformity correction surgery for kyphosis. Twelve spine surgeons from the Asia-Pacific region (six different countries) independently evaluated and classified the deformity types and proposed their surgical recommendations. This information was then compared with standard deformity classification and surgical recommendations.

Received Jan 12, 2020; Revised Apr 30, 2020; Accepted May 22, 2020

Corresponding author: Ajoy Prasad Shetty

Department of Spine Surgery, Ganga Hospital, 313, Mettupalayam Road, Coimbatore, 641043 India

Tel: +91-4222485000, Fax: +91-422-2451444, E-mail: ajoyshetty@gmail.com 
Results: The kappa coefficients for the classification were as follows: 0.88 for type $1 \mathrm{~A}, 0.78$ for type $1 \mathrm{~B}, 0.50$ for type $2 \mathrm{~B}, 0.40$ for type 3A, 0.63 for type 3B, and 0.86 for type $3 \mathrm{C}$ deformities. The overall kappa coefficient for the classification was 0.68 . Regarding the repeatability of osteotomy recommendations, kappa values were the highest for Ponte's (Schwab type 2) osteotomy (kappa 0.8). Kappa values for other osteotomy recommendations were 0.52 for pedicle subtraction/disc-bone osteotomy (Schwab type 3/4), 0.42 for vertebral column resection (VCR, type 5), and 0.30 for multilevel VCRs (type 6).

Conclusions: Excellent accuracy was found for types 1A, 1B, and $3 \mathrm{C}$ deformities (ends of spectrum). There was more variation among surgeons in differentiating between one-column (types 2A and 2B) and two-column (types $3 \mathrm{~A}$ and $3 \mathrm{~B}$ ) deficiencies, as surgeons often failed to recognize the radiological signs of posterior column failure. This failure to identify column deficiencies can potentially alter kyphosis management. There was excellent consensus among surgeons in the recommendation of type 2 osteotomy; however, some variation was observed in their choice for other osteotomies.

Keywords: Rajasekaran's kyphosis classification; Column deficiencies; Corrective osteotomy; Sagittal imbalance; Facetal subluxation or dislocation

\section{Introduction}

Kyphotic deformities of the spine are complex surgical problems and can develop secondary to multitudinous pathologies [1-5]. Although degenerative scoliosis and spondyloarthropathies diffusely involve almost the entire spine [6,7], pathologies in other congenital, postinfective, posttraumatic, or iatrogenic deformities tend to be predominantly limited to a few vertebral segments [3-5]. In addition, although some of these deformities such as ankylosing spondylitis are associated with the underlying rigid spine [6], certain conditions such as postinfective or posttraumatic kyphosis occur consequent to bony or soft tissue deficiencies of the involved vertebrae [3-5]. Considering such diverse associated issues, an appropriate management of these deformities necessitates a complete understanding and a thorough assessment of all global and local factors related to the spinal column [1-7]. Therefore, the development of a universal nomenclature and a classification system incorporating each of these individual factors is of utmost significance to ensure the best possible treatment protocol for managing these complicated sagittal deformities [8-11].

The classifications proposed by King et al. [10] and Lenke et al. [11] have standardized and streamlined the management of coronal deformities in idiopathic scoliosis. However, such comprehensive classifications that could guide the management protocol in sagittal kyphotic deformities were not available in the past [9]. An ideal classification system helps in good communication among physicians, and such a system should be simple and easy to apply, reproduce, and focus specifically on the characteristics that are most relevant to the treatment planning and prognostication [8]. In 2018, Rajasekaran et al. [9] had proposed the new classification system, taking into consideration major factors, including flexibility of the spine, magnitude of the sagittal deformity, extent of deficiency of the anterior or posterior vertebral columns, and the osteotomy type that would be typically recommended for the deformity. This classification has demonstrated good reliability and accuracy when applied among surgeons in the parent institution. However, till date, no study has analyzed the inter-rater reliability of this classification among surgeons from different institutions. Therefore, the present international, multicentered, collaborative research project involving 12 spine surgeons from six different countries was conducted to evaluate the interobserver reliability of this classification, the diagnostic accuracy of each type of deformity, and the reliability of treatment recommendations based on this classification.

\section{Materials and Methods}

A total of 30 sets of images, including plain whole spine radiographs (anteroposterior and lateral views), computed tomography scans, and magnetic resonance imaging scans, were classified based on the novel kyphosis clas- 


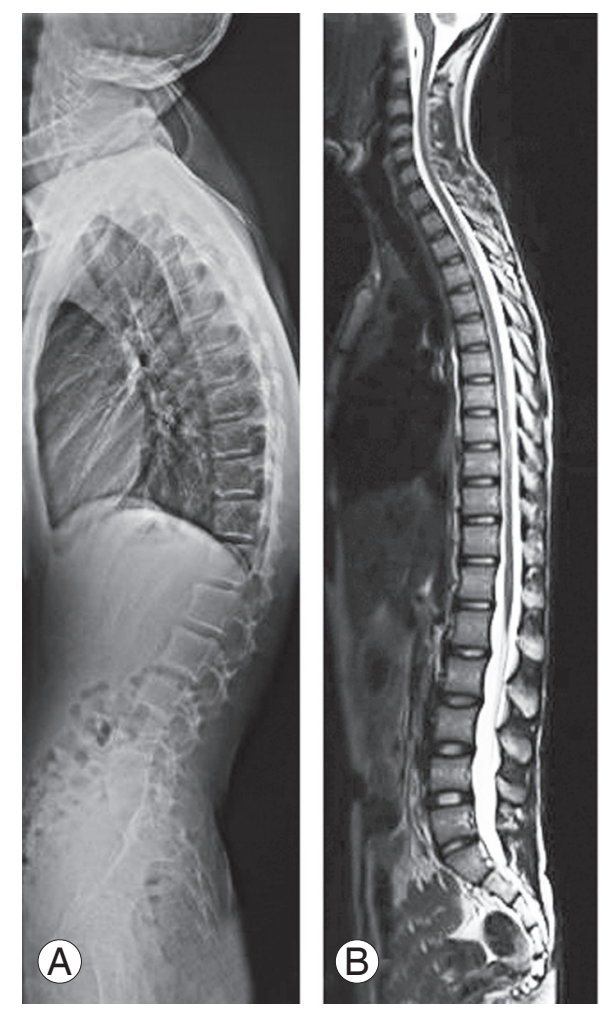

Type $1 \mathrm{~A}$
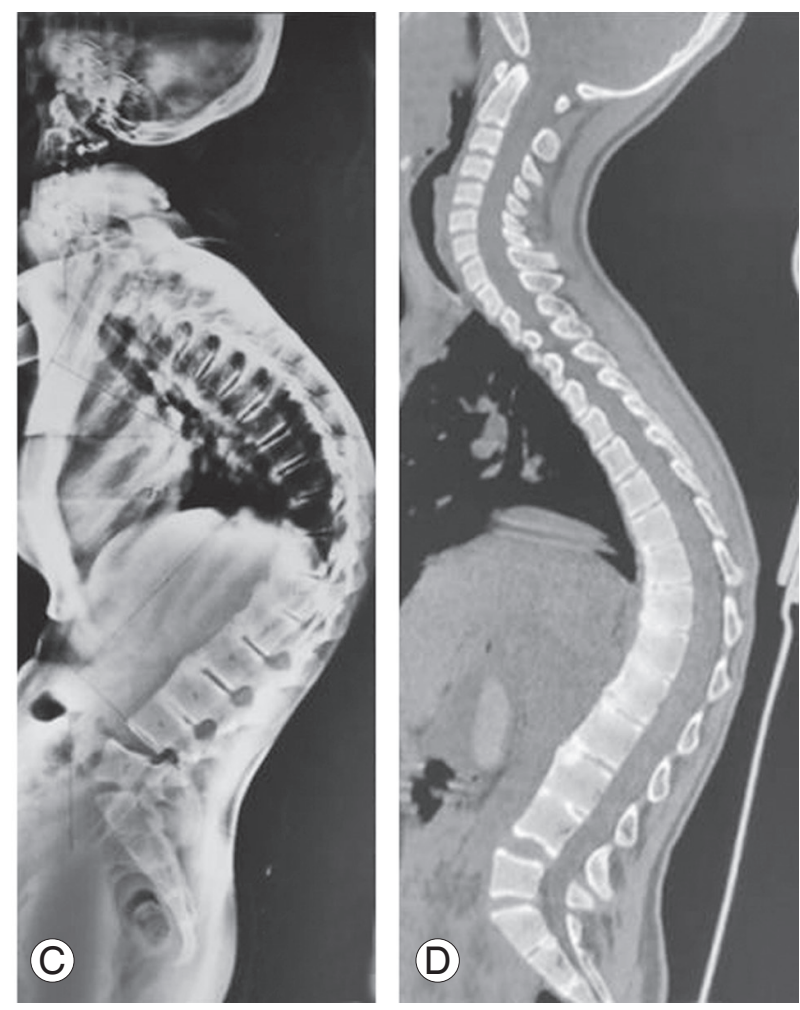

Type 1B

Fig. 1. (A) Whole spine lateral radiograph showing type $1 \mathrm{~A}$ kyphotic deformity with rounded kyphosis. (B) T2WI sequence of magnetic resonance imaging showing midsagittal section of the whole spine revealing intact column integrity and open disc spaces (type 1A). (C) Whole spine lateral radiograph showing type 1B kyphotic deformity with rounded kyphosis, fused vertebral segments, and immobile disc spaces. (D) Whole spine computed tomography showing midsagittal section with type 1B deformity revealing fused vertebral segments and immobile disc spaces.

sification system as described by Rajasekaran et al. [9]. This is a morphology-based classification system based on the following major factors: (1) extent of anterior and posterior deficiency, (2) magnitude of curve deformity, (3) flexibility of spine, and (4) type of osteotomy (Figs. 1-5).

All images were classified initially by one senior spine registrar and one senior spine fellow, who are well trained in this classification system independently, and further ratified by two senior authors (A.P.S. and R.M.K.), both from the same institution as the primary developer of this classification. These recommendations were considered as the standard for the purpose of analysis. Institutional Review Board approval was obtained from the institute of the primary investigator (IRB approval no., 2019/02/01; Ganga Medical Center and Hospital, Coimbatore, India), from where all the images were obtained, before the commencement of this study. All patients provided written informed consent for the publication of clinical details and images.

Based on the column deficiency, the curves were broadly classified as type 1 (no column deficiency), type 2 (one-column [anterior or posterior] deficiency), and type 3 (both columns deficient). Type 1 curves were further subdivided as follows: $1 \mathrm{~A}$ (flexible disc spaces present) and 1B (immobile disc spaces; e.g., ankylosing spondylitis). Type 2 curves were subdivided based on the column that is deficient as follows: $2 \mathrm{~A}$ (deficient anterior column only) and $2 \mathrm{~B}$ (deficient posterior column only). Type 3 curves were further subclassified into the following three categories: $3 \mathrm{~A}\left(\mathrm{Cobb}\right.$ angle $\left.<60^{\circ}\right) 3 \mathrm{~B}\left(\right.$ Cobb angle $\left.>60^{\circ}\right)$, and $3 \mathrm{C}$ (buckling collapse present). Two additional modifiers were included in this classification, one for global sagittal balance and the other for coronal deformity. The global sagittal balance was assigned $\mathrm{M}$ - (sagittal vertical axis [SVA] deviation of $<5 \mathrm{~cm})$ or $\mathrm{M}+(\mathrm{SVA} \geq 5 \mathrm{~cm})$. The coronal modifiers were $\mathrm{C}$ - for coronal Cobb angle $<20^{\circ}$ and $\mathrm{C}+$ for coronal Cobb angle $\geq 20^{\circ}$. Based on the recommendations of this classification system, the management protocol for each deformity type was put forth.

We shared all the images with 12 different spine sur- 

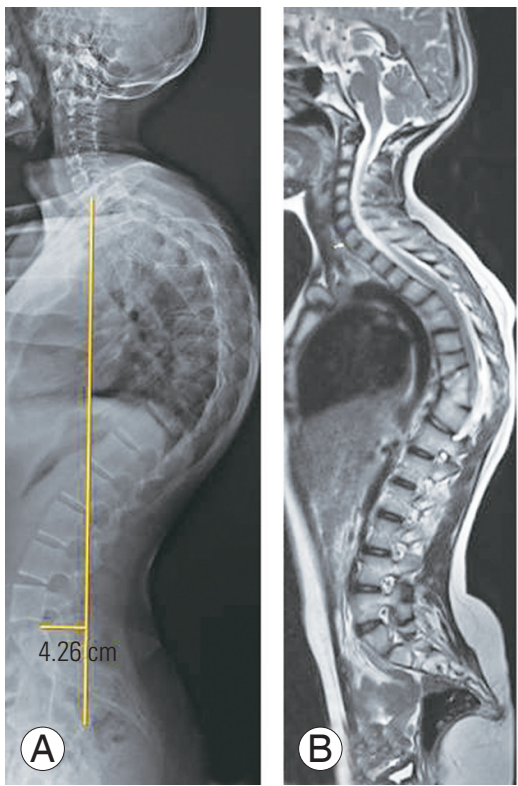

Type $1 \mathrm{~A}$
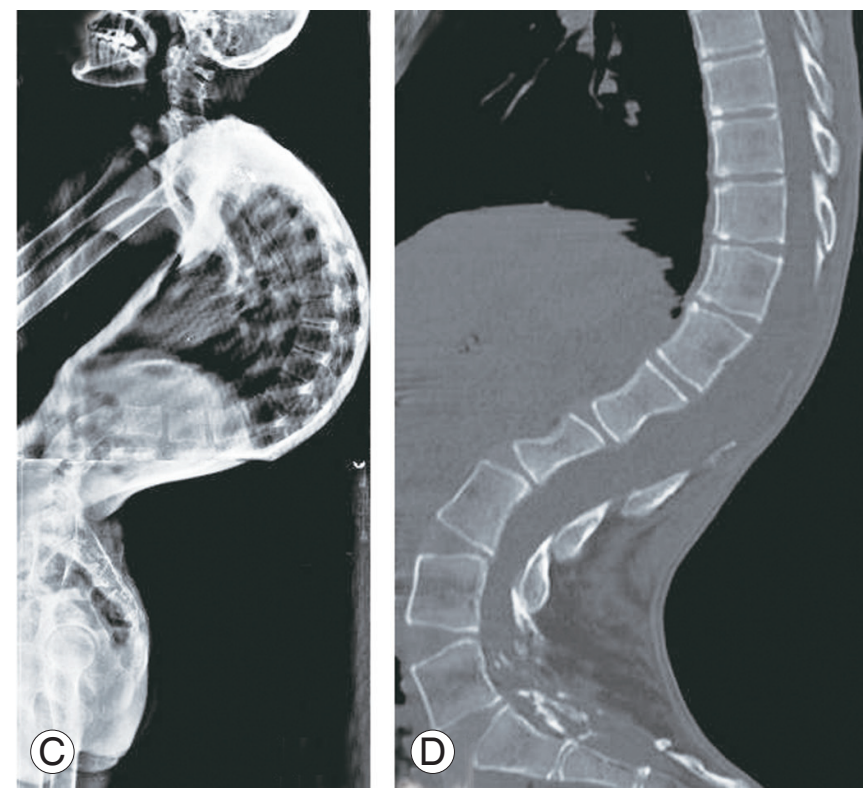

Type 1B

Fig. 2. (A) Whole spine lateral radiograph showing type 2A kyphotic deformity with rounded kyphosis and deficient anterior spinal column. (B) T2WI sequence of magnetic resonance imaging showing midsagittal section of the whole spine revealing deficient anterior column and intact posterior column integrity (type 2A). (C) Whole spine lateral radiograph showing type 2B kyphotic deformity with rounded kyphosis, deficient posterior column (post-laminectomy), and intact anterior column integrity. (D) Whole spine computed tomography showing midsagittal section with type 2B kyphotic deformity and deficient posterior column (post-laminectomy).
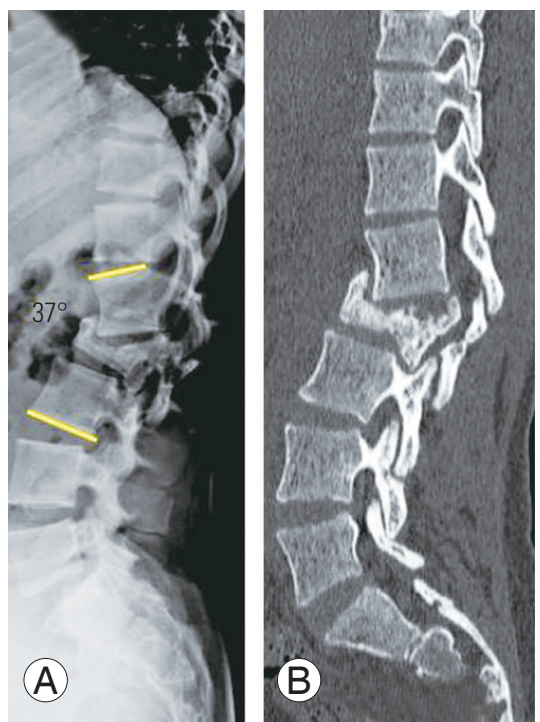

Type 3A

Fig. 3. (A) Lateral thoracolumbar radiograph revealing type $3 \mathrm{~A}$ deformity with involvement of both anterior and posterior columns (functional failure) and Cobb angle $<60^{\circ}$. (B, C) Computed tomography scan (parasagittal sections at the facet level) and T2WI sequence of magnetic resonance imaging showing midsagittal section of thoracolumbar spine revealing type $3 \mathrm{~A}$ deformity and bicolumnar failure.
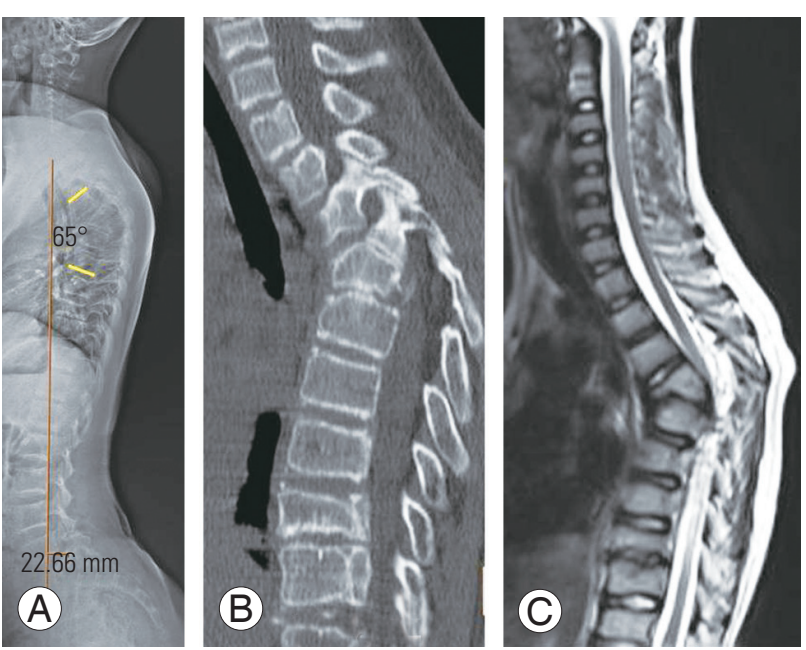

Type 3B

Fig. 4. (A) Whole spine lateral radiograph showing type 3B kyphotic deformity and angular kyphosis with deficient anterior and posterior columns and Cobb angle $>60^{\circ}$. (B, C) Computed tomography scan (parasagittal sections at the facet level) and T2WI sequence of magnetic resonance imaging showing midsagittal section of thoracolumbar spine revealing type 3B deformity and bicolumnar failure. 

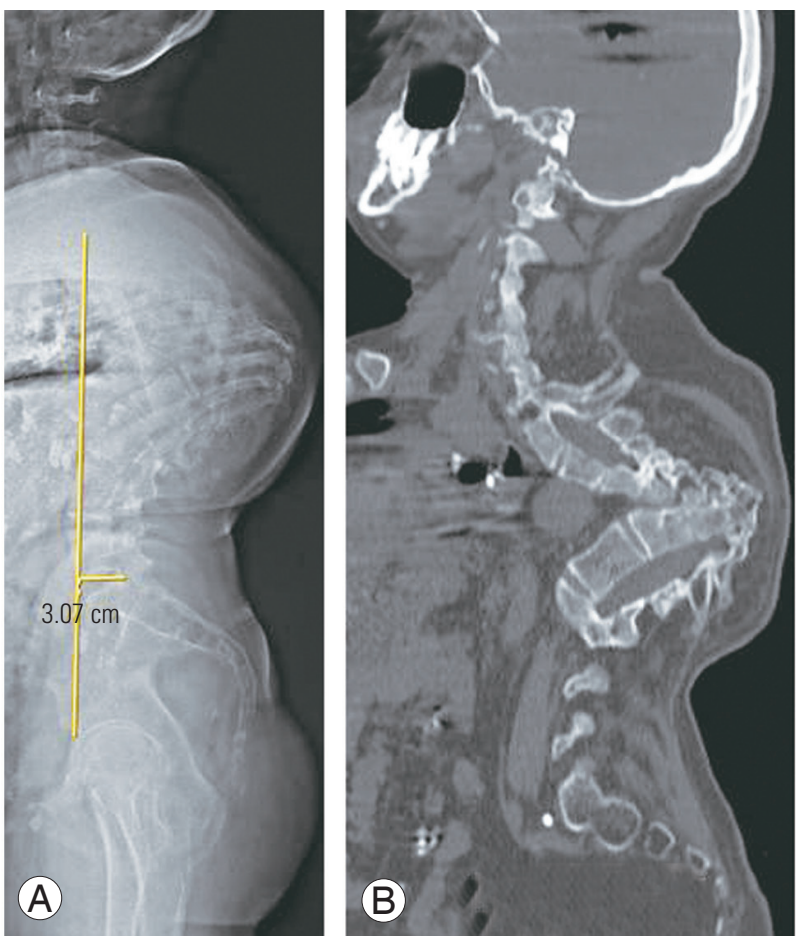

Type 3C

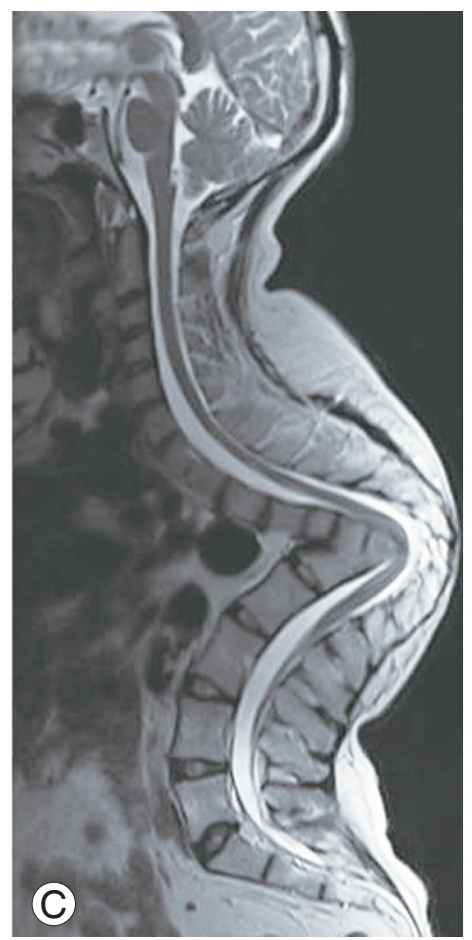

C

Fig. 5. (A) Whole spine lateral radiograph showing type 3C kyphotic deformity and angular kyphosis with buckling collapse. (B, C) Computed tomography scan (parasagittal sections at the facet level) and T2WI sequence of magnetic resonance imaging showing midsagittal section of whole spine revealing type $3 \mathrm{C}$ deformity and severe buckling collapse.

geons from the Asia-Pacific region in three different phases. The surgeons were initially educated about the classification system by sharing detailed power-point presentations describing the classification and osteotomy recommendations. This multicentered study was supported by the financial grant provided by the Asia-Pacific Spine Society.

Next, a questionnaire was shared with each participant spine surgeon involving the following questions: (1) What is the type of deformity based on kyphosis classification (as described by Rajasekaran et al. [9]); (2) What is the global sagittal modifier (M- or $\mathrm{M}+$ )?; (3) What is the coronal modifier (C- or $\mathrm{C}+$ )?; and (4) What is the surgical approach or intervention that you would consider for this deformity (including any additional procedures)?

All the questions and responses from each responder were entered on the online survey development cloudbased software "SurveyMonkey" (SurveyMonkey, San Mateo, CA, USA). All responses and entries made in the registry were blinded. After the completion of all the three phases of data collection, the obtained data were compiled by two independent researchers (one senior fellow and one junior spine consultant). All data were analyzed and presented, vide infra.

The inter-rater reliability and accuracy were calculated (by comparing each evaluator's recommendations with the standard recommendations) for each type of deformity and surgical recommendations using percentage (\%) correlation and kappa (Cohen and Fleiss) correlation, Kendall correlation coefficient, and intraclass correlation. Furthermore, the internal consistency among the evaluators was compared using Cronbach's a correlation and correlation matrices.

\section{Results}

We received responses from all 12 volunteers during phase 1 evaluation, from 11 volunteers during phase 2 evaluation, and from only 10 volunteers during phase 3 evaluation (Table 1). For detailed validation analyses, complete evaluations from only the first 10 respondents could be included. Based on our evaluations (by surgeons of our institution), there were six patients with type 1 deformity, two patients with type 2 deformity, and 22 patients with 
Table 1. Distribution of categories of deformities classified by the evaluators

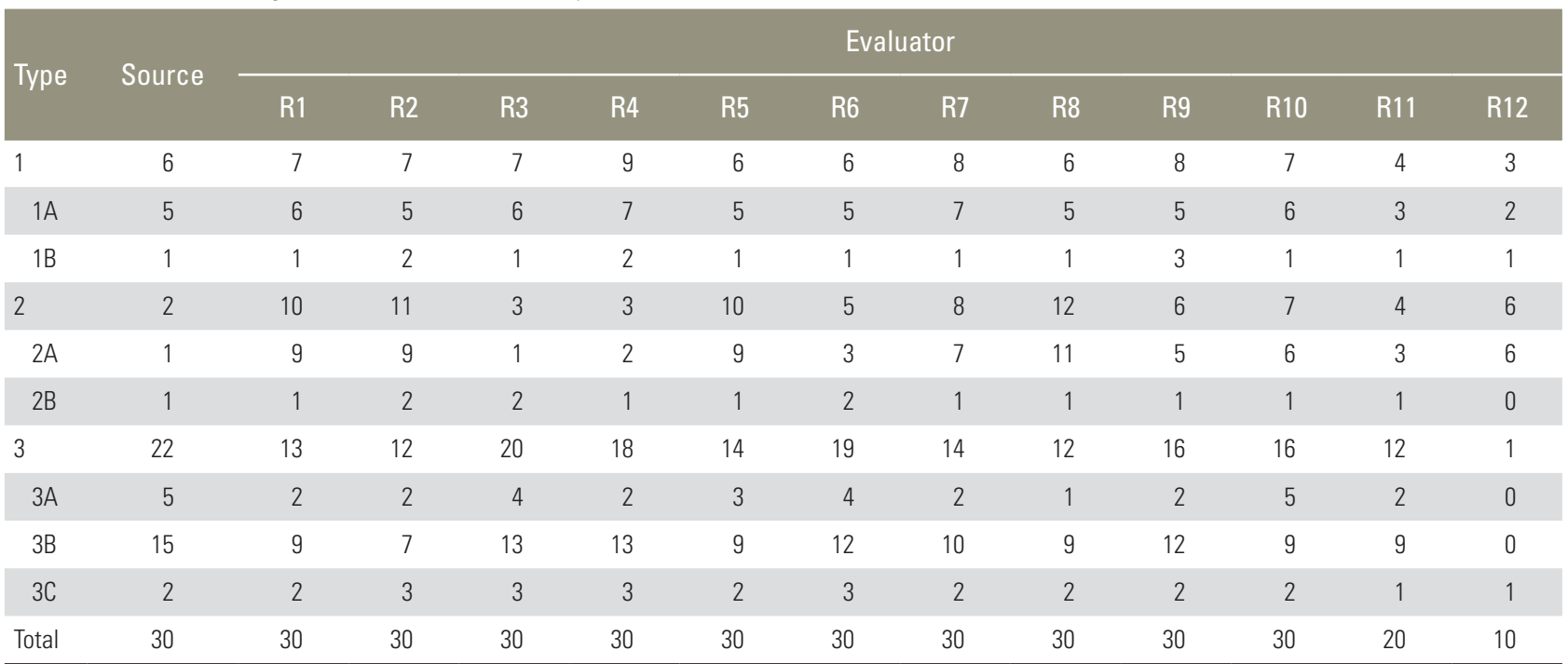

type 3 deformity. Thus, a majority of patients belonged to type 3 deformity.

\section{Deformity classification}

With respect to the type of deformity, the surgeons of the parent institution had classified five deformities as type $1 \mathrm{~A}$, one each under types $1 \mathrm{~B}, 2 \mathrm{~A}$, and $2 \mathrm{~B}$; five deformities as type 3A; 15 deformities as type 3B; and two deformities as type $3 \mathrm{C}$. Among those patients whom the surgeons of the parent institution had classified as having types $1 \mathrm{~A}$ and $1 \mathrm{~B}$ deformities, $86.4 \%$ and $83.3 \%$ of the respondents had classified under the same category, respectively. Similarly, among the deformities that were diagnosed by the parent institution surgeons as types $2 \mathrm{~A}$ and $2 \mathrm{~B}, 50 \%$ and $58.3 \%$ were classified by the volunteers under the same subtypes, respectively. Among those patients whose deformities were classified under types $3 \mathrm{~A}, 3 \mathrm{~B}$, and $3 \mathrm{C}, 33.9 \%$, $67.1 \%$, and $95.5 \%$ were also respectively classified under the same category by the other evaluators. The distribution of the different types of deformity, as classified by each surgeon, is shown in Tables 1 and 2.

Overall, when the response of each evaluator (with regard to the deformity type) was individually compared with the standard, the percentage correlation ranged between $56.7 \%$ and $86.7 \%$, and Cohen's kappa coefficient ranged between 0.43 and 0.81 (Kendall coefficient ranged between 0.73 and 0.90 , and intraclass correlation coefficient was 0.97 ) (Table 3). Excellent inter-rater reliability is defined by a kappa coefficient $>0.80$. We observed a fairly good internal consistency among the evaluators based on Cronbach's a ranging between 0.958 and 0.963 (Table 3 ).

There was an excellent consistency between the surgeons in the reporting of types $1 \mathrm{~A}, 1 \mathrm{~B}$, and $3 \mathrm{C}$ deformities (kappa coefficients, $0.88,0.78$, and 0.86 , respectively). There was moderate consistency and repeatability with respect to types $2 \mathrm{~B}$ and $3 \mathrm{~B}$ deformities (kappa coefficients, 0.50 and 0.63 , respectively). Low reliability was observed for deformities of types $2 \mathrm{~A}$ and $3 \mathrm{~A}$. The kappa coefficient for type $2 \mathrm{~A}$ deformities could not be reported because of only a single case in this category and significant variation among the respondents. The kappa coefficient for type $3 \mathrm{~A}$ deformities was 0.40 (Table 4 ). For each type of deformity as classified by the surgeons of the parent institution, the classification proposed by each of the volunteer is also shown in Table 2.

\section{Global sagittal balance and coronal deformities}

The deformities were classified on the basis of global sagittal and coronal modifiers as $\mathrm{M}$ - and $\mathrm{M}+$ and $\mathrm{C}$ - and $\mathrm{C}+$. There were five patients who were classified under $\mathrm{M}+$ and $\mathrm{C}+$ categories each and 25 patients each under M- and Ccategories. The distribution of the classification of global sagittal and coronal modifiers among the spine surgeons is presented in Table 3. Among those patients whom the parent institution surgeons had classified into $\mathrm{C}+$ and $\mathrm{C}$ categories, $76.8 \%$ (43 of 56 responses) and 98.9\% (271 of 
Table 2. Comparison of the proposed types of kyphosis: standard versus evaluators

\begin{tabular}{|c|c|c|c|c|c|c|c|c|c|c|c|c|}
\hline \multirow{2}{*}{ Source } & \multicolumn{12}{|c|}{ Evaluator } \\
\hline & R1 & $\mathrm{R} 2$ & R3 & $\mathrm{R} 4$ & $\mathrm{R} 5$ & R6 & $\mathrm{R7}$ & $\mathrm{R} 8$ & R9 & R10 & R11 & R12 \\
\hline $1 A-5$ & $1 \mathrm{~A}-5$ & $\begin{array}{l}1 \mathrm{~A}-4 \\
2 \mathrm{~B}-1\end{array}$ & $1 A-5$ & $1 A-5$ & $1 A-5$ & $1 \mathrm{~A}-5$ & $1 A-5$ & $1 \mathrm{~A}-5$ & $1 \mathrm{~A}-5$ & $\begin{array}{l}1 \mathrm{~A}-4 \\
2 \mathrm{~A}-1\end{array}$ & $\begin{array}{l}1 \mathrm{~A}-2 \\
1 \mathrm{~B}-1\end{array}$ & $1 \mathrm{~A}-1$ \\
\hline 1B-1 & 1B-1 & 1B-1 & 1B-1 & 1B-1 & 1B-1 & 1B-1 & $1 \mathrm{~A}-1$ & 1B-1 & 1B-1 & 1B-1 & $1 \mathrm{~A}-1$ & 1B-1 \\
\hline $2 A-1$ & $1 \mathrm{~A}-1$ & 1B-1 & $1 \mathrm{~A}-1$ & $2 A-1$ & $3 A-1$ & $2 A-1$ & $2 A-1$ & $2 \mathrm{~A}-1$ & $3 B-1$ & $2 A-1$ & - & - \\
\hline $2 \mathrm{~B}-1$ & $2 B-1$ & 2B-1 & 2B-1 & $1 \mathrm{~A}-1$ & $2 B-1$ & 2B-1 & 1B-1 & 2B-1 & 1B-1 & $1 \mathrm{~A}-1$ & $2 \mathrm{~B}-1$ & $1 \mathrm{~A}-1$ \\
\hline \multirow[t]{5}{*}{$3 A-5$} & $2 A-3$ & $1 \mathrm{~A}-1$ & $2 A-1$ & $1 \mathrm{~A}-1$ & $2 A-3$ & $2 A-2$ & $1 \mathrm{~A}-1$ & $2 \mathrm{~A}-4$ & $2 A-2$ & $1 \mathrm{~A}-1$ & $2 A-3$ & $2 A-4$ \\
\hline & $3 A-2$ & $2 A-3$ & $3 A-4$ & $2 A-1$ & $3 A-2$ & $3 A-3$ & $2 A-2$ & $3 A-1$ & $2 B-1$ & $2 A-2$ & $3 \mathrm{~A}-1$ & \\
\hline & & $3 A-1$ & & 2B-1 & & & $2 B-1$ & & $3 A-2$ & $3 A-2$ & 3B-1 & \\
\hline & & & & $3 A-1$ & & & $3 A-1$ & & & & & \\
\hline & & & & 3B-1 & & & & & & & & \\
\hline \multirow[t]{5}{*}{ 3B-15 } & $2 A-6$ & $2 A-6$ & $3 B-14$ & 1B-1 & $2 A-6$ & 2B-1 & $2 A-4$ & $2 A-6$ & 1B-1 & $2 A-2$ & $3 A-1$ & $2 A-2$ \\
\hline & $3 B-9$ & $3 A-1$ & $3 \mathrm{C}-1$ & $3 A-1$ & $3 B-9$ & $3 A-1$ & $3 A-1$ & $3 B-9$ & $2 A-3$ & 2B-1 & $3 B-8$ & \\
\hline & & 3B-7 & & 3B-12 & & 3B-12 & 3B-10 & & 3B-11 & $3 A-3$ & & \\
\hline & & $3 C-1$ & & $3 C-1$ & & $3 \mathrm{C}-1$ & & & & 3B-8 & & \\
\hline & & & & & & & & & & $3 \mathrm{C}-1$ & & \\
\hline \multirow[t]{2}{*}{$3 \mathrm{C}-2$} & $3 C-2$ & $3 C-2$ & $3 C-2$ & $3 C-2$ & $3 C-2$ & $3 C-2$ & $3 C-2$ & $3 C-2$ & $3 C-2$ & 3B-1 & $3 C-1$ & $3 C-1$ \\
\hline & & & & & & & & & & $3 C-1$ & & \\
\hline
\end{tabular}

Table 3. Comparison of the classification: standard versus evaluators: kappa coefficient

\begin{tabular}{|c|c|c|c|c|c|c|c|}
\hline Evaluator & $\%$ & $\begin{array}{l}95 \% \text { Confidence } \\
\text { interval }\end{array}$ & Cohen's kappa & $p$-value & $\begin{array}{c}\text { Kendall correlation } \\
\text { coefficient }\end{array}$ & $p$-value & $\begin{array}{l}\text { Cronbach a } \\
\text { correlation }\end{array}$ \\
\hline R1 & 66.7 & $47.2-82.7$ & 0.57 & $<0.001$ & 0.74 & $<0.001$ & 0.960 \\
\hline R2 & 53.3 & $34.3-71.7$ & 0.43 & $<0.001$ & 0.66 & $<0.001$ & 0.963 \\
\hline R3 & 86.7 & $69.3-96.2$ & 0.81 & $<0.001$ & 0.90 & $<0.001$ & 0.958 \\
\hline R4 & 73.3 & $54.1-87.7$ & 0.63 & $<0.001$ & 0.81 & $<0.001$ & 0.960 \\
\hline R5 & 66.7 & $47.2-82.7$ & 0.58 & $<0.001$ & 0.69 & $<0.001$ & 0.960 \\
\hline R6 & 83.3 & $65.3-94.4$ & 0.77 & $<0.001$ & 0.89 & $<0.001$ & 0.959 \\
\hline R7 & 63.3 & 43.9-80.1 & 0.52 & $<0.001$ & 0.80 & $<0.001$ & 0.959 \\
\hline R8 & 66.7 & $47.2-82.7$ & 0.58 & $<0.001$ & 0.76 & $<0.001$ & 0.963 \\
\hline R9 & 70 & $50.6-85.3$ & 0.60 & $<0.001$ & 0.73 & $<0.001$ & 0.963 \\
\hline R10 & 56.7 & $37.4-74.5$ & 0.44 & $<0.001$ & 0.73 & $<0.001$ & 0.961 \\
\hline
\end{tabular}

274 responses) of the respondents also classified in a similar manner, respectively. Among those patients whom the surgeons of the parent institution had classified into $\mathrm{M}+$ and M- categories, $82.5 \%$ (47 of 57 responses) and $89.4 \%$ (244 of 273 responses) of the respondents also classified under the same category, respectively. Our observations indicated good reproducibility in the interpretation of the global sagittal and coronal modifiers (Table 5).

\section{Type of osteotomy or deformity correction required}

Based on the recommendations purported by Rajasekaran et al. [9], the type of osteotomy for each deformity was also discussed. The surgeons of the parent institution had 
recommended type 2 (Ponte) osteotomy in five patients (16.7\%), type 3 or 4 (pedicle subtraction/disc-bone osteotomy, PSO/DBO) in seven patients (23.3\%), type 5 (vertebral column resection, VCR) in 12 patients (40\%), type

Table 4. Consistency in the reporting of each deformity type among the evaluators (versus standard)

\begin{tabular}{lcc} 
Response & Fleiss kappa coefficient & $p$-value \\
1A & 0.88 & $<0.001$ \\
1B & 0.78 & $<0.001$ \\
\hline 2A & NR & NR \\
2B & 0.50 & $<0.001$ \\
3A & 0.40 & $<0.001$ \\
3B & 0.63 & $<0.001$ \\
\hline 3C & 0.86 & $<0.001$ \\
\hline Overall kappa coefficient & 0.68 & $<0.001$ \\
\hline Overall Kendall coefficient & 0.77 & $<0.001$ \\
\hline Overall intraclass correlation & 0.97 & $<0.001$ \\
\hline
\end{tabular}

$\mathrm{NR}$, not reportable.
6 (multilevel VCRs) in five patients (16.7\%), and staged VCR (halo-gravity traction followed by VCR) in one patient (3.3\%) (Table 6).

We received a total of 342 responses from the different participating spine surgeons who recommended their preferred surgical interventions for each deformity. The total recommended surgical interventions included 73 (21.3\%) Ponte's osteotomies, 90 (26.3\%) PSO/DBOs, 115 (33.6\%) VCRs, 49 (14.3\%) multilevel VCRs, 12 (3.5\%) anterior insitu fusions with graft, and $2(0.5 \%)$ staged VCRs (halogravity traction followed by VCR). For one patient, one of the surgeons had recommended no surgical deformity correction. For nine deformities, five surgeons had recommended more than one surgical option. One of these deformities was classified as type $1 \mathrm{~A}$, one was classified as type $2 \mathrm{~B}$, five were classified under type $3 \mathrm{~B}$, and two were classified under type 3C.

Among those patients for whom the parent institution surgeons had recommended type 2 (Ponte) osteotomy, type 3 or 4 (PSO/DBO), type 5 (VCR), type 6 (multilevel VCR), anterior in-situ fusion with graft, and two-staged

Table 5. Additional modifiers: standard versus evaluators

\begin{tabular}{|c|c|c|c|c|c|c|c|c|c|c|c|c|c|}
\hline \multirow{2}{*}{ Category } & \multirow{2}{*}{ Source } & \multicolumn{12}{|c|}{ Evaluator } \\
\hline & & $\mathrm{R} 1$ & $\mathrm{R} 2$ & R3 & $\mathrm{R} 4$ & $\mathrm{R} 5$ & $\mathrm{R} 6$ & $\mathrm{R} 7$ & $\mathrm{R} 8$ & $\mathrm{Rg}$ & $\mathrm{R} 10$ & $\mathrm{R} 11$ & $\mathrm{R} 12$ \\
\hline $\mathrm{M}_{+}$ & $5(16.7)$ & $5(16.7)$ & $6(20.0)$ & $10(33.3)$ & $5(16.7)$ & $6(20.0)$ & $6(20.0)$ & $10(33.3)$ & $5(16.7)$ & $8(26.7)$ & $7(23.3)$ & $6(30.0)$ & $2(20.0)$ \\
\hline M- & 25 (83.3) & 25 (83.3) & 24 (80.0) & $20(66.7)$ & $25(83.3)$ & $24(80.0)$ & $24(80.0)$ & $20(66.7)$ & 25 (83.3) & 22 (73.3) & $23(76.7)$ & $14(70.0)$ & $8(80.0)$ \\
\hline $\mathrm{C}_{+}$ & $5(16.7)$ & 0 & $4(13.3)$ & $5(16.7)$ & $4(13.3)$ & $5(16.7)$ & $6(20.0)$ & $6(20.0)$ & $4(13.3)$ & $4(13.3)$ & $5(16.7)$ & $3(15.0)$ & $1(10.0)$ \\
\hline C- & 25 (83.3) & $30(100.0)$ & $26(86.7)$ & 25 (83.3) & $26(86.7)$ & 25 (83.3) & $24(80.0)$ & $24(80.0)$ & $26(86.7)$ & $26(86.7)$ & 25 (83.3) & $17(85.0)$ & $9(90.0)$ \\
\hline
\end{tabular}

Values are presented as number (\%).

Table 6. Surgical osteotomy options: standard versus evaluators

\begin{tabular}{|c|c|c|c|c|c|c|c|c|c|c|c|c|c|}
\hline \multirow{2}{*}{ Variable } & \multirow{2}{*}{ Source } & \multicolumn{12}{|c|}{ Evaluator } \\
\hline & & R1 & $\mathrm{R} 2$ & $\mathrm{R} 3$ & R4 & R5 & R6 & $\mathrm{R7}$ & R8 & $\mathrm{R} 9$ & $\mathrm{R} 10$ & $\mathrm{R} 11$ & $\mathrm{R} 12$ \\
\hline Type 2 (Ponte) & 5 & 8 & 6 & 6 & 6 & 7 & 5 & 10 & 6 & 5 & 6 & 5 & 3 \\
\hline Types 3 or 4 (PSO/DBO) & 7 & 6 & 8 & 7 & 6 & 9 & 7 & 6 & 10 & 13 & 9 & 4 & 5 \\
\hline Type 5 (VCR) & 12 & 7 & 7 & 14 & 11 & 10 & 15 & 13 & 13 & 8 & 11 & 5 & 1 \\
\hline Type 6 (multi-level VCR) & 5 & 8 & 7 & 6 & 4 & 8 & 2 & 1 & 0 & 3 & 4 & 5 & 1 \\
\hline Anterior in-situ fusion & 0 & 1 & 2 & 0 & 2 & 2 & 1 & 1 & 1 & 1 & 0 & 1 & 0 \\
\hline No surgery & 0 & 0 & 0 & 0 & 1 & 0 & 0 & 0 & 0 & 0 & 0 & 0 & 0 \\
\hline Halo+VCR & 1 & 1 & 0 & 0 & 0 & 0 & 0 & 0 & 0 & 0 & 0 & 1 & 0 \\
\hline Total & 30 & 31 & 30 & 33 & 30 & 36 & 30 & 31 & 30 & 30 & 30 & 21 & 10 \\
\hline
\end{tabular}

PSO/DBO, pedicle subtraction/disc-bone osteotomy; VCR, vertebral column resection. 
Table 7. Comparison of the proposed osteotomy: standard versus evaluators: kappa coefficient

\begin{tabular}{lccccccc} 
Evaluator & $\%$ & $\begin{array}{c}95 \% \text { Confidence } \\
\text { interval }\end{array}$ & Cohen's kappa & $p$-value & $\begin{array}{c}\text { Kendall correlation } \\
\text { coefficient }\end{array}$ & $\begin{array}{c}\text { Cronbach } \alpha \\
\text { correlation }\end{array}$ \\
\hline R1 & 56.7 & $37.4-74.5$ & 0.43 & $<0.001$ & 0.72 & $<0.001$ & 0.974 \\
\hline R2 & 66.7 & $47.2-82.7$ & 0.56 & $<0.001$ & 0.79 & $<0.001$ & 0.973 \\
\hline R3 & 83.3 & $65.3-94.4$ & 0.77 & $<0.001$ & 0.88 & $<0.001$ & 0.975 \\
R4 & 73.3 & $54.1-87.7$ & 0.64 & $<0.001$ & 0.85 & $<0.001$ & 0.973 \\
\hline R5 & 53.3 & $34.3-71.7$ & 0.38 & 0.0001 & 0.70 & $<0.001$ & 0.974 \\
\hline R6 & 73.3 & $54.1-87.7$ & 0.6 & $<0.001$ & 0.76 & $<0.001$ & 0.974 \\
\hline R7 & 56.7 & $37.4-74.5$ & 0.39 & 0.0001 & 0.62 & $<0.001$ & 0.977 \\
R8 & 63.3 & $43.9-80.1$ & 0.48 & $<0.001$ & 0.60 & $<0.001$ & 0.974 \\
\hline R9 & 60 & $40.6-77.3$ & 0.46 & $<0.001$ & 0.66 & $<0.001$ & 0.976 \\
\hline R10 & 50 & $3.3-68.7$ & 0.30 & $<0.0028$ & 0.53 & $<0.001$ & 0.977 \\
\hline
\end{tabular}

Table 8. Consistency in the reporting of osteotomy type among the evaluators (versus standard)

\begin{tabular}{lcc} 
Response & Kappa coefficient & $p$-value \\
\hline Type 2 (Ponte) osteotomy & 0.80 & $<0.001$ \\
\hline Type 3 or 4 (PSO/DBO) osteotomy & 0.52 & $<0.001$ \\
\hline Type 5 (VCR) & 0.42 & $<0.001$ \\
Type 6 (multiple VCR) osteotomy & 0.30 & $<0.001$ \\
Overall kappa coefficient & 0.50 & $<0.001$ \\
Overall Kendall coefficient & 0.04 & $<0.001$ \\
\hline Overall intra-class correlation & 0.98 & $<0.001$ \\
\hline
\end{tabular}

PSO/DBO, pedicle subtraction/disc-bone osteotomy; VCR, vertebral column resection.

VCR (based on the classification), the evaluators concurred with the standard on $96.3 \%, 67.5 \%, 64.1 \%, 45.5 \%$, and $10 \%$ of the cases, respectively. When each respondent's choices were compared with the standard, the percentage correlation coefficient ranged between $50 \%$ and $83.3 \%$ and the kappa correlation ranged between 0.3 and 0.77 (Table 7). Among them, the evaluators showed a fair degree of internal consistency in their choice for osteotomy based on Cronbach's a correlation ranging between 0.973 and 0.977 (Table 7). With respect to the osteotomy choices, there was an excellent inter-rater correlation for the recommendation of type 2 osteotomy (kappa coefficient $=0.80$ ). However, for the other procedures, the kappa value was quite low (ranging between 0.3 and 0.52 ) (Table 8 ).

\section{Discussion}

Unlike scoliosis, kyphotic deformities occur due to a multitude of etiologies and are frequently accompanied by varying degrees of deficiency of the anterior and posterior columns, which determine the prognosis and management decisions [12-14]. In 2018, Rajasekaran et al. [9] proposed a kyphosis classification system based on column deficiency, curve magnitude, and osteotomy requirement. They incorporated the six different types of surgical osteotomies described by Schwab [15] and also added a seventh option of anterior fusion with strut grafts without major correction for patients with buckling collapse. They also demonstrated good correlation with their classification and the complexity of the osteotomy required. However, the results were derived from a single center and no multicenter validation was available. Through the present study, we are providing the results from a multicenter validation on the interobservor correlation for various types with classification and also the correlation with the surgeon's choice of osteotomy.

\section{Deformity classification}

As previously mentioned, the rationale behind the current classification is that the greater the loss of column integrity, the more complex is the kyphotic deformity. In type 1 deformity, the columns are intact; in type 2 deformity, the integrity of one column is violated; and in type 3 deformities, the integrities of both columns are lost. In the present study, there was an excellent consistency among the sur- 
geons in the reporting of type $1 \mathrm{~A}, 1 \mathrm{~B}$, and $3 \mathrm{C}$ deformities. There was moderate consistency and repeatability with regard to types $2 \mathrm{~B}$ and $3 \mathrm{~B}$ deformities. However, for types $2 \mathrm{~A}$ and $3 \mathrm{~A}$ deformities, we observed a lower inter-rater accuracy.

Most of these variations were secondary to the discrepancies in distinguishing between single- and two-column deficiencies. Although the surgeons of the parent institution had classified only two deformities under type 2 category and 20 deformities under type $3 \mathrm{~A}$ or $3 \mathrm{~B}$ category, a significant proportion of these type 3 deformities were classified by the other respondents under type 2 category. This variation was caused due to surgeons concentrating primarily on the anterior column in their radiological assessment and failing to notice posterior column failure either by facet subluxation or by frank dislocation. However, the differentiation between types 2 and 3 deformities is clinically very important as it has important biomechanical implications and changes the management protocol. In general, among type 2 deformities, type $2 \mathrm{~A}$ deformity involves the loss of integrity of only the anterior column $[3,4]$. When such deformities are caused secondary to the partial loss of vertebrae, the kyphosis is gradual. However, when there is a complete loss of one or more vertebrae, angular kyphosis ensues [16]. Type 2B deformities result from posterior soft tissue (tension band) or posterior bony loss (e.g., laminectomy) [17,18]. Type 3 deformities, involving the loss of both columns, have a poor prognosis for curve progression, instability, and buckling collapse [19]. Whenever there is a type 3 curve of magnitude $>60^{\circ}$, there is a relatively greater risk for progression, instability, and buckling collapse [2]. In type $2 \mathrm{~A}$ deformities, although the deficiency of the anterior column is structural,

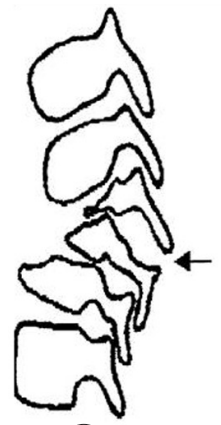

(A)

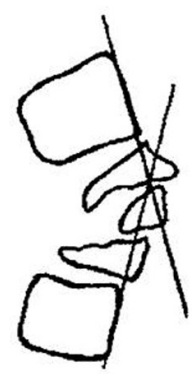

(B)

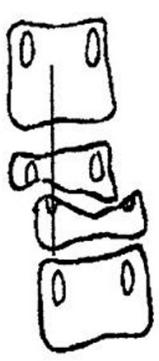

(C)

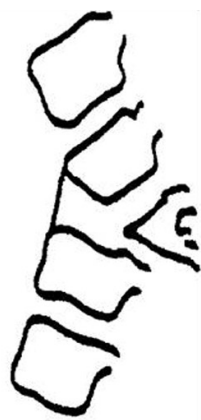

(D)
Fig. 6. Spine at risk signs [23]. (A) Facet subluxation or dislocation (arrow). (B) Posterior vertebral body retropulsion. (C) Lateral translation. (D) Anterior toppling sign. the progression of the deformity can lead to functional failure of the posterior column (predominantly involving facet subluxation or dislocation). Such deformities must be promptly recognized as "impending type 3A deformities," as described in our original article [9]. We do believe that in any patient with kyphosis $>60^{\circ}$ magnitude and positive "spine at risk" signs (described by Rajasekaran [20] for the prediction of progression of pediatric kyphosis), the loss of posterior column should be strongly suspected (Fig. 6).

\section{Intactness of posterior column}

The classification is based on the integrity and extent of loss of columns; hence, the accurate identification of the column loss is important. We found that there was no discrepancy in the assessment at the two ends of the spectrum-where there is no column loss (types $1 \mathrm{~A}$ and $1 \mathrm{~B}$ ) or where there was a severe loss of both columns (type 3C). The major emphasis of the current classification is the identification of the intactness or deficiency of posterior column based on radiological findings.

The biomechanics of the spine, especially in children, is determined by the "Euler's laws of slender column" [21]. Evaluation of impairment of the posterior column is of utmost significance in understanding the evolution of type 3 kyphotic deformities. Although the loss of anterior column is always structural, the failure of the posterior column in several instances is consequent to a functional failure involving facet subluxation. Pathologies such as tuberculosis, congenital vertebral anomalies, achondroplasia, and posttraumatic kyphosis can present with perched, subluxed, or dislocated facets, which leads to confusion between type $2 \mathrm{~A}$ and type $3 \mathrm{~A}$ deformities. In biomechanical terms, failure of both columns is termed as "death of the column" following which precipitous collapse and increase in deformity are predicted. Although surgeons are quite adept at identifying the structural loss of the anterior column, there is often a lack of recognition to identify a posterior column failure or facet dislocation [22,23]. This was the reason for the low interobserver agreement value and the more frequent classification under type 2 category in cases that were actually type 3. Figs. 7 and 8 demonstrate two such cases that were classified originally as types $3 \mathrm{~A}$ and $3 \mathrm{~B}$, respectively (according to the standard recommendation). However, the classification of the deformity in these two patients by the participant spine 

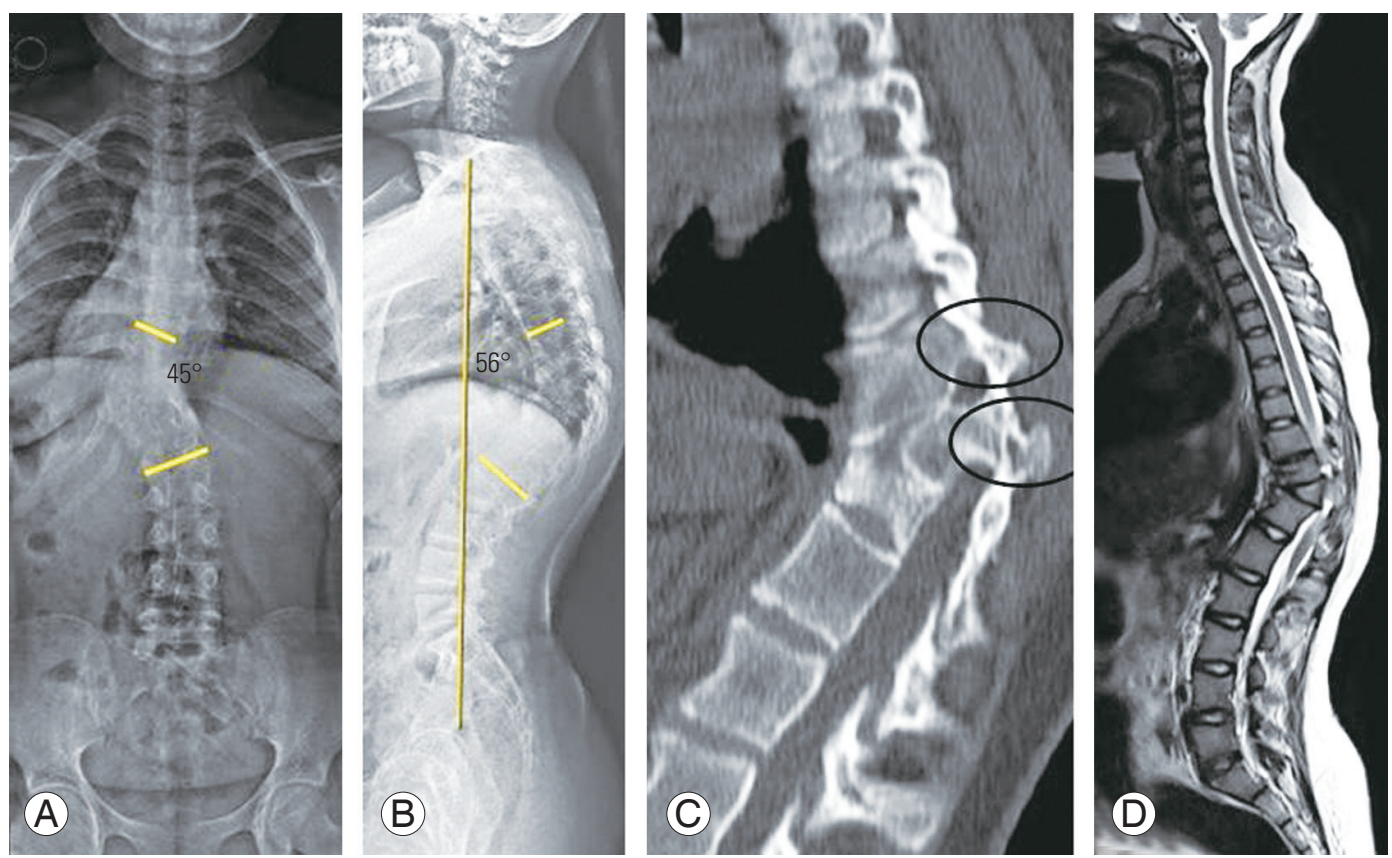

Fig. 7. (A, B) Whole spine posteroanterior and lateral radiographs depicting congenital left TL kyphoscoliosis with T11 posterolateral hemivertebra. (C, D) Computed tomography and T2WI-magnetic resonance imaging parasagittal sections at TL region depicting facet subluxation and evidence of functional posterior column failure. The Cobb angle on the lateral radiograph measured $56^{\circ}$. This deformity strictly belongs to kyphosis type $3 \mathrm{~A}$ under the Rajasekaran et al. [9] classification system. However, only $18 \%$ of the respondents classified this deformity as type $3 \mathrm{~A}$, and $73 \%$ and $9 \%$ of the respondents classified it as types $2 \mathrm{~A}$ and $3 \mathrm{~B}$, respectively. TL, thoracolumbar.
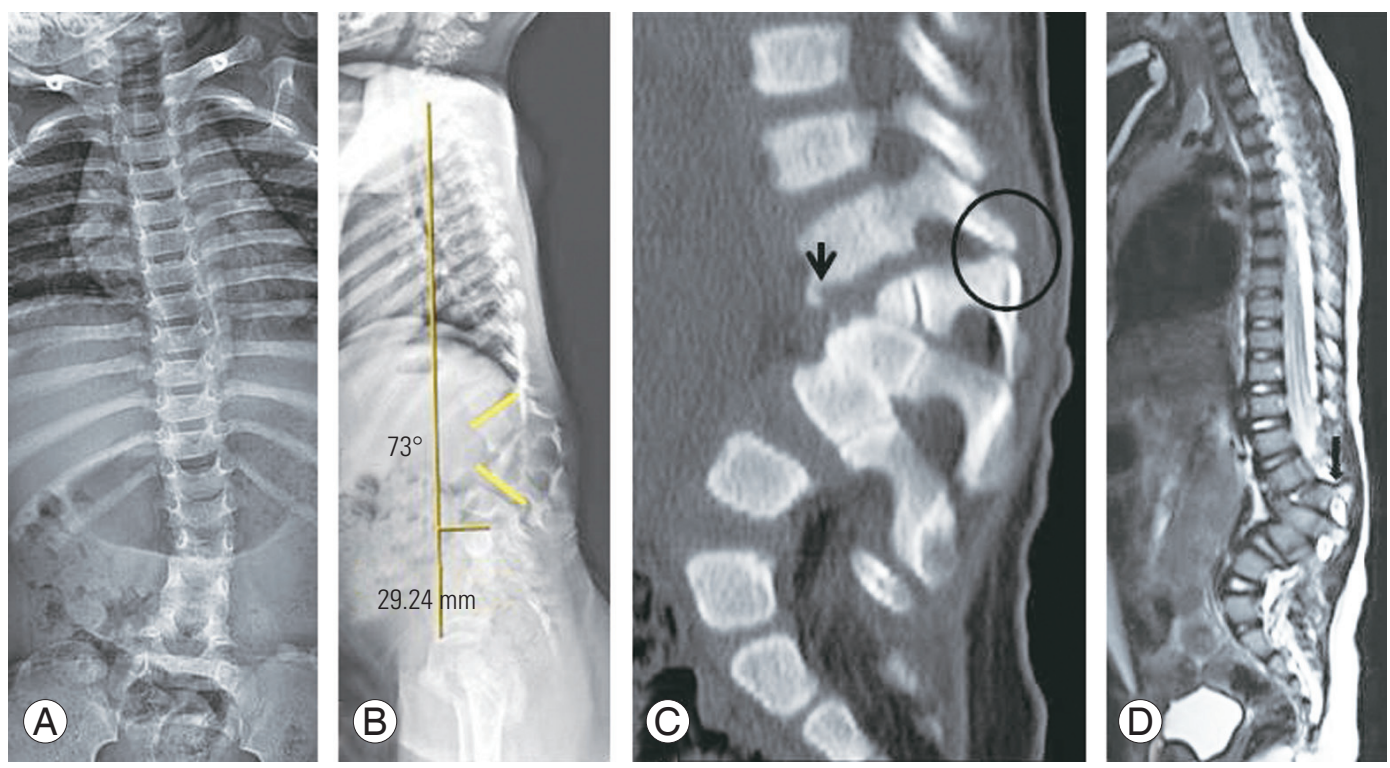

Fig. 8. (A, B) Whole spine posteroanterior and lateral radiographs depicting complex, congenital lumbar formation-segmentation defects with severe kyphotic deformity. The lumbar Cobb angle measures $73^{\circ}$. (C) Parasagittal computed tomography sections revealing bifacet subluxation and anterior vertebral toppling at the L1-2 level. (D) Midsagittal sections of T2WI-magnetic resonance imaging revealing anterior vertebral toppling and posterior vertebral body retropulsion at the L1-2 level. This deformity strictly belongs to kyphosis type 3B under the Rajasekaran et al. [9] classification system. However, only 63.6\% of the respondents classified this kyphosis as type 3B, and the remaining $36.4 \%$ of them classified it as type $2 \mathrm{~A}$. 
surgeons varied significantly due to the inconsistencies in the recognition of the posterior column discontinuity. Although the imaging shown in Fig. 7 (type 3A) was classified under types $3 \mathrm{~A}, 2 \mathrm{~A}$, and $3 \mathrm{~B}$ by $18 \%, 73 \%$, and $9 \%$ of the respondents, respectively, the type $3 \mathrm{~B}$ deformity shown in Fig. 8 was classified as types 3B and 2A by $63.6 \%$ and $36.4 \%$ of the respondents, respectively.

We consider this issue not as a problem of the classification but as an important clinical value of the classification itself, as it will now help surgeons focus on the status of the facet and accurately classify patients belonging to type 3. This will benefit patients through early and appropriate intervention and prevent progression under observation.

\section{Global sagittal balance and coronal modifiers}

The global sagittal balance is an important parameter to be considered in the management of kyphotic deformities. As the ultimate goal of managing these deformities is to optimally restore the anatomical sagittal profile of the patient, the significance of including this radiological parameter into any kyphosis classification system cannot be understated [24,25]. We included a deviation of $>5 \mathrm{~cm}$ in both directions (positive or negative sagittal imbalance) under sagittal imbalance ( $\mathrm{M}+$ global sagittal modifier). Another parameter, which is of utmost importance in assessing any sagittal spinal deformity, is the associated coronal deformity [26,27]. We included a cut-off value of $20^{\circ}$ to include patients with significant coronal deformity $(\mathrm{C}+)$. These two parameters are components of the Scoliosis Research Society-Schwab adult spinal deformity classification. Knowledge of these two parameters not only helps in providing greater uniformity to kyphosis nomenclature but also helps in evaluating the overall balance of the spinal column and devising appropriate management strategies for these deformities. As mentioned earlier, there was good consensus among the assessors in describing these modifiers.

We observed a significant correlation among the respondents regarding the classification of global sagittal and coronal modifiers in these patients. The surgeons of the parent institution had classified five patients each under $\mathrm{M}+$ (global sagittal modifier) and $\mathrm{C}+$ (coronal modifier) categories, respectively. Overall, there was good (82.5\% and $77 \%$, respectively) repeatability in classifying the "global sagittal" and "coronal" modifiers.

\section{Type of osteotomy or deformity correction required}

Based on our classification, we made recommendations for the osteotomy and the correction technique for each kyphotic deformity type. In type 1 curves, the deformity correction typically involves Schwab type 2 (if disc spaces are open) or type 3/4 (if disc spaces are fused) osteotomies. In type 2 deformities, the osteotomy is proposed based on the magnitude of the deformity. In type $2 \mathrm{~A}$ deformities of $<30^{\circ}$ magnitude, Schwab type 2 osteotomies may be recommended, and in type $2 \mathrm{~A}$ deformities of $>30^{\circ}$ magnitude and type $2 \mathrm{~B}$ deformities, type 3 or 4 osteotomies may be required. In type $3 \mathrm{~A}$ or $3 \mathrm{~B}$ deformities, Schwab type 4, 5, or 6 osteotomies are necessary. When buckling collapse (type 3C) develops, staged deformity correction procedures or in-situ fusions generally offer the safest outcome. The rationale underlying these recommendations is the progressive degrees of curve complexity and the need for more complex corrective measures with each deformity type.

The surgeons of the parent institution had recommended Schwab type 5 (VCR) osteotomy in $40 \%$ (12 patients), types 3 or 4 (PSO/DBO) osteotomy in $23.3 \%$ (seven patients), types 2 (Ponte) and 6 (multilevel VCRs) osteotomies in $16.7 \%$ (five patients) each, and multistaged osteotomy in one patient. Among the total 342 responses from the participating spine surgeons, 33.6\% (115) of the recommended procedures were type 5 (VCR) osteotomies, $26.3 \%$ (90) were types 3 or 4 (PSO/DBO) osteotomies, $21.3 \%$ (73) were type 2 (Ponte) osteotomies, $14.3 \%$ (49) were type 6 (multilevel VCRs), and 3.5\% included anterior in-situ fusions. The consensus among the evaluators was excellent for deformities requiring type 2 osteotomies. However, a wide variation was detected among the surgeons regarding the choice of PSO and vertebrectomy. This can be explained by their institutional preferences and surgeons' experience. Similarly, the anterior strut grafting without major correction procedure is a valuable option in very severe cases where any form of correction will be dangerous. However, this is not very frequently performed and hence several surgeons opt for the other alternative of vertebrectomy.

\section{Limitations}

The major limitation of this study was the relatively smaller number of cases, with the significantly smaller number 
of patients belonging to types $2 \mathrm{~A}$ and $2 \mathrm{~B}$. No formal power analysis was performed to select the number of patients under each subgroup. Further studies may be planned in future to validate the kyphosis classification system, considering these drawbacks. All the entries by the respondents were made on the online "SurveyMonkey" software program in a blinded manner. Any stratification of the experience of spine surgeons and its correlation with their understanding of the classification was out of scope of this study.

\section{Conclusions}

Based on our results, there was excellent accuracy in the assessment of the deformities at the two ends of the spectrum, namely types 1A, 1B (with no column deficiency), and $3 \mathrm{C}$ (severe loss of both columns). However, surgeons classified more severe type 3 deformities as type 2, frequently not identifying facet subluxation or dislocation. Following this classification will prevent this error and help the surgeon to intervene appropriately.

\section{Conflict of Interest}

No potential conflict of interest relevant to this article was reported.

\section{Funding}

This work was sponsored by financial grant provided by Asia-Pacific Spine Society.

\section{Author Contributions}

Principal investigator: APS; senior evaluator: APS, RMK; data collection and organization: RR; manuscript preparation and statistical analysis: VKV; participant evaluator: KW, HSC, JPYC, YH, MKK, CCW, GL, SB, AN, JNB, BG; manuscript overview: KW, HSC, RMK, JPYC, YH, MKK, CCW, GL, SB, AN, JNB, BG; and supervision of manuscript preparation: APS.

\section{References}

1. Mummaneni PV, Deutsch H, Mummaneni VP. Cervicothoracic kyphosis. Neurosurg Clin N Am 2006;17:277-87.
2. Rajasekaran S. The problem of deformity in spinal tuberculosis. Clin Orthop Relat Res 2002;(398):8592.

3. Issack PS, Boachie-Adjei O. Surgical correction of kyphotic deformity in spinal tuberculosis. Int Orthop 2012;36:353-7.

4. Munting E. Surgical treatment of post-traumatic kyphosis in the thoracolumbar spine: indications and technical aspects. Eur Spine J 2010;19 Suppl 1:S69-73.

5. Van Royen BJ, De Gast A. Lumbar osteotomy for correction of thoracolumbar kyphotic deformity in ankylosing spondylitis: a structured review of three methods of treatment. Ann Rheum Dis 1999;58:399406.

6. Ravinsky RA, Ouellet JA, Brodt ED, Dettori JR. Vertebral osteotomies in ankylosing spondylitis-comparison of outcomes following closing wedge osteotomy versus opening wedge osteotomy: a systematic review. Evid Based Spine Care J 2013;4:18-29.

7. Macagno AE, O'Brien MF. Thoracic and thoracolumbar kyphosis in adults. Spine (Phila Pa 1976) 2006;31(19 Suppl):S161-70.

8. Van Middendorp JJ, Audige L, Hanson B, Chapman JR, Hosman AJ. What should an ideal spinal injury classification system consist of?: a methodological review and conceptual proposal for future classifications. Eur Spine J 2010;19:1238-49.

9. Rajasekaran S, Rajoli SR, Aiyer SN, Kanna R, Shetty AP. A classification for kyphosis based on column deficiency, curve magnitude, and osteotomy requirement. J Bone Joint Surg Am 2018;100:1147-56.

10. King HA, Moe JH, Bradford DS, Winter RB. The selection of fusion levels in thoracic idiopathic scoliosis. J Bone Joint Surg Am 1983;65:1302-13.

11. Lenke LG, Edwards CC 2nd, Bridwell KH. The Lenke classification of adolescent idiopathic scoliosis: how it organizes curve patterns as a template to perform selective fusions of the spine. Spine (Phila Pa 1976) 2003;28:S199-207.

12. Bridwell KH, Lewis SJ, Rinella A, Lenke LG, Baldus C, Blanke K. Pedicle subtraction osteotomy for the treatment of fixed sagittal imbalance: surgical technique. J Bone Joint Surg Am 2004;86-A Suppl 1:44-50.

13. Gupta MC, Kebaish K, Blondel B, Klineberg E. Spinal osteotomies for rigid deformities. Neurosurg Clin N Am 2013;24:203-11.

14. Chang KW, Cheng CW, Chen HC, Chang KI, Chen 
TC. Closing-opening wedge osteotomy for the treatment of sagittal imbalance. Spine (Phila Pa 1976) 2008;33:1470-7.

15. Schwab F, Blondel B, Chay E, et al. The comprehensive anatomical spinal osteotomy classification. Neurosurgery 2014;74:112-20.

16. Wang XB, Lenke LG, Thuet E, Blanke K, Koester LA, Roth M. Deformity angular ratio describes the severity of spinal deformity and predicts the risk of neurologic deficit in posterior vertebral column resection surgery. Spine (Phila Pa 1976) 2016;41:1447-55.

17. Fassett DR, Clark R, Brockmeyer DL, Schmidt MH. Cervical spine deformity associated with resection of spinal cord tumors. Neurosurg Focus 2006;20:E2.

18. Yeh JS, Sgouros S, Walsh AR, Hockley AD. Spinal sagittal malalignment following surgery for primary intramedullary tumours in children. Pediatr Neurosurg 2001;35:318-24.

19. Rajasekaran S. Buckling collapse of the spine in childhood spinal tuberculosis. Clin Orthop Relat Res 2007;460:86-92.

20. Rajasekaran S. The natural history of post-tubercular kyphosis in children: radiological signs which predict late increase in deformity. J Bone Joint Surg Br 2001;83:954-62.

21. Patwardhan AG, Bunch WH, Meade KP, Vanderby R Jr, Knight GW. A biomechanical analog of curve progression and orthotic stabilization in idiopathic scoliosis. J Biomech 1986;19:103-17.
22. Rajasekaran S, Vijay K, Shetty AP. Single-stage closing-opening wedge osteotomy of spine to correct severe post-tubercular kyphotic deformities of the spine: a 3-year follow-up of 17 patients. Eur Spine J 2010;19:583-92.

23. Boachie-Adjei O, Yankey K. The use of halo-gravity traction and vertebral column resection to treat children with severe kyphosis, results and complications. Ann Pediatr Child Health 2017;5:1129.

24. Schwab F, Patel A, Ungar B, Farcy JP, Lafage V. Adult spinal deformity-postoperative standing imbalance: how much can you tolerate?: an overview of key parameters in assessing alignment and planning corrective surgery. Spine (Phila Pa 1976) 2010;35:2224-31.

25. Blondel B, Schwab F, Bess S, et al. Posterior global malalignment after osteotomy for sagittal plane deformity: it happens and here is why. Spine (Phila Pa 1976) 2013;38:E394-401.

26. Cecchinato R, Berjano P, Aguirre MF, Lamartina C. Asymmetrical pedicle subtraction osteotomy in the lumbar spine in combined coronal and sagittal imbalance. Eur Spine J 2015;24 Suppl 1:S66-71.

27. Toyone T, Shiboi R, Ozawa T, et al. Asymmetrical pedicle subtraction osteotomy for rigid degenerative lumbar kyphoscoliosis. Spine (Phila Pa 1976) 2012;37:1847-52. 